\title{
Cyclooxygenase-2 gene polymorphisms and the risk of colorectal cancer: A population-based study
}

\author{
HONGXIA LI ${ }^{*}$, QINYUE GUO $^{1 *}, \mathrm{BO}_{\mathrm{ZHOU}}^{2}$ and SHUIXIANG HE ${ }^{1}$ \\ Departments of ${ }^{1}$ Gastroenterology and ${ }^{2}$ Respiration, The First Affiliated Hospital of Medical School of \\ Xi'an Jiaotong University, Xi'an, Shaanxi 710061, P.R. China
}

Received August 25, 2014; Accepted May 12, 2015

DOI: $10.3892 / \mathrm{ol} .2015 .3477$

\begin{abstract}
The aim of the present study was to determine the association between polymorphisms in the cyclooxygenase-2 (COX-2) gene promoter region, rs20417 G/C and rs2745557 G/A, and the susceptibility to colorectal cancer (CRC) in a Han Chinese population in Shaanxi, China. Polymerase chain reaction and restriction fragment length polymorphism (PCR-RFLP) were used to detect the polymorphisms of COX-2, rs20417 G/C and rs2745557 G/A, in 300 patients with CRC and 300 healthy individuals in the present case-control study. The results revealed that for the COX-2 rs20417 G/C polymorphism, the GC+CC allele frequency was $80 \%$ in CRC patients and $71 \%$ in healthy controls [odds ratio $(\mathrm{OR})=1.63 ; 95 \%$ confidence interval $(\mathrm{CI})$, 1.12-2.38; $\mathrm{P}=0.01]$. For the $\mathrm{COX}-2 \mathrm{rs} 2745557 \mathrm{G} / \mathrm{A}$ polymorphism, the GA+AA allele frequency was $84 \%$ in CRC patients and $73 \%$ in healthy controls $(\mathrm{OR}=1.94 ; 95 \% \mathrm{CI}, 1.30-2.90$; $\mathrm{P}<0.01)$. In addition, among individuals with a smoking history, drinking history or family history of CRC, those who were COX-2 rs20417 (GC+CC) or COX-2 rs2745557 (GA+AA) carriers had a significantly increased risk of developing CRC compared with that of GG genotype carriers $(\mathrm{P}<0.05)$. Furthermore, the
\end{abstract}

Correspondence to: $\mathrm{Dr}$ Shuixiang He, Department of Gastroenterology, The First Affiliated Hospital of Medical School of Xi'an Jiaotong University, 277 Yenta West Road, Xi'an, Shaanxi 710061, P.R. China

E-mail: heshuixiangxian@163.com

Dr Bo Zhou, Department of Respiration, The First Affiliated Hospital of Medical School of Xi'an Jiaotong University, 277 Yenta West Road, Xi'an, Shaanxi 710061, P.R. China

E-mail: zb_bob@163.com

Abbreviations: CRC, colorectal cancer; PCR-RFLP, polymerase chain reaction and restriction fragment length polymorphism; COX, cyclooxygenase; SNP, Single-nucleotide polymorphism; OR, odds ratio; $\mathrm{CI}$, confidence interval

\section{${ }^{*}$ Contributed equally}

Key words: colorectal cancer, cyclooxygenase-2, polymerase chain reaction and restriction fragment length polymorphism, single-nucleotide polymorphisms allelic frequencies of COX-2 rs20417 G/C and rs2745557 G/A in patients with lymph node metastasis in stage III/IV of CRC were significantly different from those of COX-2 rs20417 G/C and rs2745557 G/A in patients without lymph node metastasis in stage $\mathrm{I} / \mathrm{II}(\mathrm{P}<0.05)$. In conclusion, the results of the present study revealed that COX-2 rs20417 C allele carriers and rs2745557 A allele carriers have a significantly increased risk of CRC compared with GG genotype carriers; in addition, the frequencies of these alleles were demonstrated to be associated with lymph node metastasis and CRC progression.

\section{Introduction}

Numerous previous studies have confirmed that patients who suffer from inflammatory diseases of the colon, including Crohn's disease and ulcerative colitis, have a markedly greater risk of colorectal cancer (CRC) (1-3). This therefore indicates that inflammation has a critical role in the pathogenesis of numerous types of cancers. The pro-inflammatory enzyme cyclooxygenase (COX), alternatively named prostaglandin endoperoxide synthases, converts arachidonic acid into prostaglandins, which have an important role in the inflammatory response (3).

There are two main isozymes of COX: COX-1, which is continuously expressed and is involved in maintaining homeostasis; and COX-2, which is primarily involved in the production of prostaglandins throughout the inflammatory response, the overexpression of which enhances proliferation, attenuates apoptosis and promotes the invasion of cancer cells, leading to angiogenesis (4-7). Previous studies have provided evidence for an association between COX-2 and certain types of cancer, including CRC, gastric cancer and esophageal carcinoma (8-10).

Single-nucleotide polymorphisms (SNP) have been detected in the COX-2 gene promoter region, including rs20417 G/C and rs2745557 G/A (11). In comparison to other SNPs, these polymorphisms have received much attention in regards to their association with the risk of cancer. It has been suggested that they may disrupt gene transcription and/or mRNA stability as well as modulate the inflammatory response, which may result in varied individual susceptibility to cancer $(12,13)$. In addition, numerous molecular epidemiological studies have evaluated the association between these COX-2 promoter polymorphisms and varied susceptibility to types of cancer among different populations; however, the results of these studies remain controversial $(14,15)$. 
One study reported that the COX-2 rs2745557 G/A SNP promoted COX-2 transcription through producing a transcriptional factor c-Myb-binding site, which in turn enhanced the risk of esophageal squamous cell carcinoma in a Chinese population (16). In addition, the COX-2 rs $20417 \mathrm{G} / \mathrm{C}$ polymorphism was reported to result in an increased risk of esophageal cancer (16). However, the functional implications of these COX-2 SNPs remain controversial $(11,17)$.

It was proposed that COX-2 genetic polymorphisms that alter protein expression and/or activity may affect the inflammatory response and in turn influence the risk of CRC. The present case-control study was performed using a population of Han Chinese CRC patients and healthy volunteers in Shaanxi, China. The study aimed to evaluate the associations of the COX-2 promoter region variants, rs $20417 \mathrm{G} / \mathrm{C}$ and rs $2745557 \mathrm{G} / \mathrm{A}$, with the susceptibility for CRC. In addition, the present study aimed to analyze the association between these genetic variants and metastatic CRC.

\section{Subjects and methods}

Study subjects and clinical characteristics. A case-control study was performed in order to evaluate the risk factors for CRC. A total of 300 CRC patients and 300 healthy controls were enrolled in the present study between October 2009 and October 2013. All subjects were of Han Chinese ethnicity and from Shaanxi, China. In addition, all CRC patients enrolled in the study were cases which had been newly diagnosed and were confirmed as colorectal adenocarcinoma through histopathological analysis; these patients were enrolled at the First Affiliated Hospital of Xi'an Jiaotong University (Xi'an, Shaanxi, China). Patients were excluded from the present study if they had a history of previous cancer diagnosis, chemotherapy or radiotherapy. At the time of diagnosis, the pathological stage of CRC was classified according to the 1987 Union for International Cancer Control Tumor-Node-Metastasis (TNM) grade classification (TNM I-IV) (18). In addition, tumor grades were classified according to the World Health Organization grade classification (19): Well differentiated, low; moderately differentiated, intermediate; and poorly differentiated, high. The control group consisted of healthy, cancer-free individuals who had attended a community cancer screening program for the early detection of cancer based, which was conducted in Shaanxi province during the time period when the cases were collected and involved physical examinations, including chest radiography, endoscopy and abdominal ultrasonography. Controls had no individual history of cancer and were frequency matched to patients based on gender and age. CRC patients and controls were asked a series of questions in order to determine demographic characteristics and potential risk factors for CRC. Written informed consent was obtained from all participants; this included their agreement to participate in the study and to allow their biological samples to be genetically analyzed. The study was approved by the Ethics Committee of Xi'an Jiao Tong University.

DNA extraction. A total of $4 \mathrm{ml}$ fasting peripheral blood was collected from all subjects and added to blood collection tubes with $\mathrm{k} 2$-EDTA anticoagulant, then stored at $-80^{\circ} \mathrm{C}$. The DNA from whole blood was extracted using a standard
Table I. Basic clinical characteristics in the CRC group and control group.

\begin{tabular}{lcc}
\hline Classified variable & Control $(\%)$ & CRC $(\%)$ \\
\hline Age, years & & \\
$<65$ & $170(56.7)$ & $162(54)$ \\
$\geq 65$ & $130(43.3)$ & $138(46)$ \\
Gender & & \\
Male & $202(67.3)$ & $209(69.7)$ \\
Female & $98(32.7)$ & $91(30.3)$ \\
Smoking history & & \\
No & $183(61)$ & $155(51.7)$ \\
Yes & $117(39)$ & $145(48.3)^{\mathrm{a}}$ \\
Drinking history & & \\
No & $117(39)$ & $87(29)$ \\
Yes & $183(61)$ & $213(71)^{\mathrm{b}}$ \\
Family history & & \\
No & $271(90.3)$ & $246(82)$ \\
Yes & $29(9.7)$ & $54(18)^{\mathrm{c}}$ \\
\hline
\end{tabular}

${ }^{a} \mathrm{P}<0.05$ vs. no smoking history; ${ }^{\mathrm{b}} \mathrm{P}<0.05$ vs. no drinking history; ${ }^{\mathrm{c}} \mathrm{P}<0.05$ vs. no family history.

proteinase $\mathrm{K}$ digestion and the phenol/chloroform method, as previously described (16).

COX-2 rs20417 G/C and rs2745557 G/A polymorphism genotype. Genomic DNA was isolated from the peripheral blood lymphocytes of each participant using the Puregene DNA Isolation Kit, according to the manufacturer's recommendation (Gentra Systems, Inc., Big Lake, MN, USA). Genotypes of the COX-2 rs20417 G/C and rs2745557 G/A polymorphisms were examined using polymerase chain reaction-based restriction fragment length polymorphism (PCR-RFLP) as previously described (16). All chemicals used were of analytical grade and were purchased from Sigma-Aldrich (St. Louis, MO, USA) unless otherwise stated. All PCRs were conducted in total volume of $25 \mu \mathrm{l}$, comprising $19.8 \mu 1 \mathrm{H}_{2} \mathrm{O}, 2.5 \mu \mathrm{l} 10 \mathrm{X}$ reaction buffer, $0.5 \mu \mathrm{ldNTP}(10 \mathrm{mM}), 0.2 \mu \mathrm{l}$ Taq DNA polymerase and $0.5 \mu \mathrm{l}$ of each forward and reverse primers $(20 \mu \mathrm{M})$. The primers were obtained from Applied Biosystems Life Technologies (Foster City, CA, USA) and the sequences were as follows: Forward, 5'-TTTAGCGTTTGTCCATCAGAAG-3' and reverse, 5'-GGGGCGAGTAAGGTTAAGAAA-3' for COX-2rs20417G/C; andforward,5'-TCAGCCATACAGGTGAGTACC-3' and reverse, 5'-CTGGGAGCAGGAAAGAACTG-3' for COX-2 rs2745557 G/A. The PCR commenced with $10 \mathrm{~min}$ at $96^{\circ} \mathrm{C}$, followed by 45 cycles of $30 \mathrm{sec}$ at $96^{\circ} \mathrm{C}, 30 \mathrm{sec}$ at $\mathrm{T}_{\mathrm{m}}\left(60-63^{\circ} \mathrm{C}\right)$ and $30 \mathrm{sec}$ at $72^{\circ} \mathrm{C}$, and finally $10 \mathrm{~min}$ at $72^{\circ} \mathrm{C}$. The genotypes determined using PCR-RFLP were confirmed through direct DNA sequencing of the PCR products from all samples using Big Dye Terminator Cycle Sequencing kit (Applied Biosystems Life Technologies) on an ABI 3500xl DNA Analyzer (Applied Biosystems Life Technologies). Genotyping was performed blind to the samples patient or 
Table II. Frequency distribution of cyclooxygenase-2 rs20417G/C in the CRC and control groups.

\begin{tabular}{lccccc}
\hline rs20417 & Control (\%) & CRC (\%) & $\chi^{2}$ & P-value & OR (95\% CI) \\
\hline GG & $87(29)$ & $60(20)$ & & & \\
GC & $104(34.7)$ & $117(39)$ & 5.20 & 0.02 & $1.63(1.07-2.49)$ \\
CC & $109(36.3)$ & $123(41)$ & 5.36 & 0.02 & $1.64(1.08-2.49)$ \\
GC+CC & $213(71)$ & $240(80)$ & 6.57 & 0.01 & $1.63(1.12-2.38)$ \\
\hline
\end{tabular}

CRC, colorectal cancer; OR, odds ratio, CI, confidence interval.

Table III. Frequency distribution of cyclooxygenase-2 rs2745557 G/A in the CRC and control groups.

\begin{tabular}{|c|c|c|c|c|c|}
\hline rs2745557 & Control (\%) & CRC (\%) & $\chi^{2}$ & P-value & OR $(95 \% \mathrm{CI})$ \\
\hline GG & $81(27)$ & $48(16)$ & & & \\
\hline GA & $105(35)$ & $123(41)$ & 9.25 & $<0.01$ & $1.98(1.27-3.08)$ \\
\hline AA & $114(38)$ & $129(43)$ & 8.52 & $<0.01$ & $1.91(1.23-2.96)$ \\
\hline $\mathrm{GA}+\mathrm{AA}$ & $219(73)$ & $252(84)$ & 10.75 & $<0.01$ & $1.94(1.30-2.90)$ \\
\hline
\end{tabular}

CRC, colorectal cancer; OR, odds ratio, CI, confidence interval.

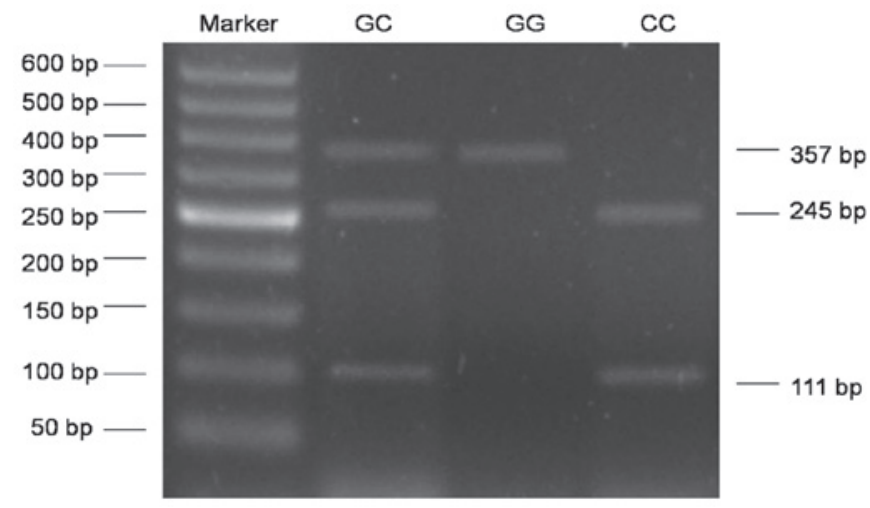

Figure 1. Cyclooxygenase-2 rs20417 G/C polymorphism genotypes, as determined using polymerase chain reaction-based restriction fragment length polymorphism.

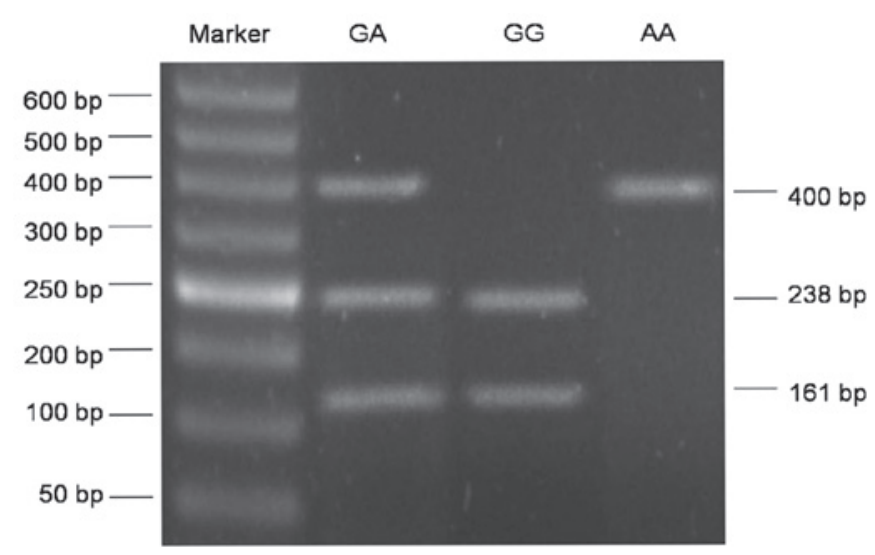

Figure 2. Cyclooxygenase-2 rs2745557 G/A polymorphism genotypes, as determined using polymerase chain reaction-based restriction fragment length polymorphism. control status; all samples were evaluated three times by different investigators and the reproducibility was $100 \%$.

Statistical analysis. Associations between COX-2 genotypes and susceptibility to CRC were calculated using odds ratios (ORs) and 95\% confidence intervals (CIs) through logistic regression. ORs were adjusted for age and gender. Differences between genotype distributions among subgroups were evaluated using $\chi^{2}$ tests. $\mathrm{P}<0.05$ was considered to indicate a statistically significant difference between values and all statistical tests were two-sided. All statistical analyses were performed using SPSS 19.0 software (International Business Machines, Armonk, NY, USA).

\section{Results}

Characteristics of the study population. The mean age of CRC patients was $60 \pm 10.21$ years and the mean age of healthy control group was $58 \pm 12.35$ years. No significant differences were identified between age and gender between the case and control groups. As shown in Fig. 1, the frequency distribution of CRC patients with a history of smoking or drinking was significantly increased compared with the healthy controls; in addition, a significant difference was detected between those with a family history of CRC in the CRC and healthy control groups $(\mathrm{P}<0.05)$.

Genotype frequencies of COX-2 rs20417 G/C and rs $2745557 \mathrm{G} / \mathrm{A}$ and their association with $C R C$ risk. The genotype of COX-2 rs20417 G/C polymorphism included GG, GC and CC. The fragments with 245 and 111 bp demonstrated a GG wild-type homozygous genotype, a single 357 bp fragment stood for the CC homozygous genotype and three fragments of 357, 245 and $111 \mathrm{bp}$ indicated the GC 
Table IV. Frequency distribution of cyclooxygenase-2 rs20417 G/C with age, gender, smoking history, drinking history and family history of CRC in the CRC and control groups.

\begin{tabular}{|c|c|c|c|c|c|}
\hline \multirow[b]{2}{*}{ Classified variable } & \multicolumn{2}{|c|}{ Control } & \multicolumn{2}{|c|}{$\mathrm{CRC}$} & \multirow[b]{2}{*}{ OR $(95 \% \mathrm{CI})$} \\
\hline & GG $(\%)$ & $\mathrm{GC}+\mathrm{CC}(\%)$ & $\mathrm{GG}(\%)$ & $\mathrm{GC}+\mathrm{CC}(\%)$ & \\
\hline \multicolumn{6}{|l|}{ Age, years } \\
\hline$<65$ & $134(44.7)$ & $36(12.0)$ & $117(39.0)$ & $45(15.0)$ & $1.43(0.87-2.37)$ \\
\hline$\geq 65$ & $106(35.3)$ & $24(8.0)$ & $101(33.7)$ & $37(12.3)$ & $1.70(0.96-3.04)$ \\
\hline \multicolumn{6}{|l|}{ Gender } \\
\hline Male & $168(56.0)$ & $34(11.3)$ & $165(55.0)$ & 44 (14.7) & $1.32(0.80-2.17)$ \\
\hline Female & $70(23.3)$ & $28(9.4)$ & 59 (19.7) & $32(10.6)$ & $1.36(0.73-2.51)$ \\
\hline \multicolumn{6}{|l|}{ Smoking history } \\
\hline No & $136(45.3)$ & 47 (15.7) & $110(36.7)$ & $45(15.0)$ & $1.18(0.73-1.91)$ \\
\hline Yes & 92 (30.7) & $25(8.3)$ & 89 (29.7) & $56(18.6)$ & $2.30(1.33-4.03)^{\mathrm{a}}$ \\
\hline \multicolumn{6}{|l|}{ Drinking history } \\
\hline No & $95(31.7)$ & $22(7.3)$ & $69(23.0)$ & $18(6.0)$ & $1.13(0.56-2.26)$ \\
\hline Yes & $164(54.7)$ & $19(6.3)$ & $158(52.7)$ & $55(18.3)$ & $3.01(1.71-5.29)^{b}$ \\
\hline \multicolumn{6}{|l|}{ Family history } \\
\hline No & $246(82.0)$ & $25(8.3)$ & $214(71.3)$ & $32(10.7)$ & $1.47(0.85-2.56)$ \\
\hline Yes & $18(6.0)$ & $11(3.7)$ & $20(6.7)$ & 34 (11.3) & $2.78(1.10-7.06)^{\mathrm{c}}$ \\
\hline
\end{tabular}

${ }^{\mathrm{a}} \mathrm{P}<0.05$ vs. no smoking history; ${ }^{\mathrm{b}} \mathrm{P}<0.05$ vs. no drinking history; ${ }^{\mathrm{C}}<0.05$ vs. no family history. $\mathrm{CRC}$, colorectal cancer; $\mathrm{OR}$, odds ratio; $\mathrm{CI}$, confidence interval.

heterozygous genotype (Fig. 1). The COX-2 rs2745557 G/A polymorphism also consisted of three genotypes: GG, GA and AA. As shown in Fig. 2, the fragments with 238 and 161 bp represented the GG homozygous wild-type genotype, the single fragment of $400 \mathrm{bp}$ depicted the AA homozygous genotype and the GA heterozygous genotype was indicated by three fragments with 400, 238 and $161 \mathrm{bp}$.

As show in Table II, GG, GC and CC allele frequencies of the COX-2 rs20417 G/C polymorphism were $29,34.7$ and $36.3 \%$, respectively, in the healthy control group and 20 , 39 and $41 \%$, respectively, in the CRC group. This therefore indicated that the observed genotype frequencies of SNPs in the two groups were in accordance with the Hardy-Weinberg equilibrium. The distribution of these genotypes and their association with CRC risk was then analyzed between the CRC and healthy control groups. For the rs20417 G/C polymorphism, the $\mathrm{GC}+\mathrm{CC}$ allele frequency was $80 \%$ in $\mathrm{CRC}$ patients and $71 \%$ in healthy controls $(\mathrm{OR}=1.63 ; 95 \% \mathrm{CI}$, 1.12-2.38; $\mathrm{P}=0.01)$.

As show in Table III, the allele frequencies of GG, GA and AA of the COX-2 rs2745557 G/A polymorphism were 27,35 and $38 \%$, respectively, in healthy controls and 16, 41 and $43 \%$, respectively, in patients with CRC. Therefore, the observed genotype frequencies of SNPs in the two groups were in accordance with the Hardy-Weinberg equilibrium. In addition, there was a significant difference in genotype distribution of the COX-2 rs2745557 G/A polymorphism between the two groups $(\mathrm{P}<0.01)$. The $\mathrm{GA}+\mathrm{AA}$ allele frequency was $84 \%$ in CRC patients and $73 \%$ in healthy controls $(\mathrm{OR}=1.94$; 95\% CI, 1.30-2.90; $\mathrm{P}<0.01)$. Based on these results, it was determined that COX-2 rs20417 C allele (GC+CC) carriers and rs2745557 A allele (GA+AA) carriers have an increased risk of CRC compared with GG genotype carriers.

Association of COX-2 rs20417 G/C and rs2745557 G/A polymorphism with age, gender, drinking history, smoking history and family history of CRC. The potential interactions between COX-2 rs20417 G/C and rs2745557 G/A polymorphisms and characteristics including age, gender, smoking history, drinking history and family history of CRC were analyzed using SPSS software. As shown in Tables IV and V, there was no statistically difference in age and gender between the CRC and healthy control groups. It was demonstrated that among subjects who had a history of smoking, those who were COX-2 rs20417 $(\mathrm{GC}+\mathrm{CC})$ carriers had a significantly greater risk of developing $\mathrm{CRC}$ in comparison with GG genotype carriers in the healthy controls $(\mathrm{OR}=2.30 ; 95 \%$ CI 1.33-4.03; $\mathrm{P}<0.05)$. In addition, COX-2 rs2745557 (GA+AA) carriers with a smoking history had an increased risk of CRC relative to that of GG genotype carriers in the healthy controls $(\mathrm{OR}=2.31 ; 95 \% \mathrm{CI}, 1.09-4.86$; $\mathrm{P}<0.05)$. For subjects with a history of drinking, COX-2 rs20417 (GC+CC) carriers exhibited a markedly increased risk of CRC compared with healthy control GG genotype carriers (OR=3.01; 95\% CI 1.71-5.29; $\mathrm{P}<0.05)$; while COX-2 rs2745557 (GA+AA) carriers also demonstrated a higher risk for CRC in comparison with GG genotype carriers in the healthy control group $(\mathrm{OR}=2.75 ; 95 \% \mathrm{CI}, 1.59-4.76 ; \mathrm{P}<0.05)$. Furthermore, in subjects with a family history of CRC, COX-2 rs20417 $(\mathrm{GC}+\mathrm{CC})$ carriers had an increased risk of CRC compared with $\mathrm{GG}$ genotype carriers in healthy controls $(\mathrm{OR}=2.78 ; 95 \%$ CI, 1.10-7.06; P<0.05); while COX-2 rs2745557 (GA+AA) carriers also exhibited an elevated risk for CRC compared with 
Table V. Frequency distribution of cyclooxygenase-2 rs2745557 G/A with age, gender, smoking history, drinking history and family history of CRC in the CRC and control groups.

\begin{tabular}{|c|c|c|c|c|c|}
\hline \multirow[b]{2}{*}{ Classified variable } & \multicolumn{2}{|c|}{ Control } & \multicolumn{2}{|c|}{ CRC } & \multirow[b]{2}{*}{ OR $(95 \% \mathrm{CI})$} \\
\hline & $\mathrm{GG}(\%)$ & $\mathrm{GC}+\mathrm{CC}(\%)$ & $\mathrm{GG}(\%)$ & $\mathrm{GC}+\mathrm{CC}(\%)$ & \\
\hline \multicolumn{6}{|l|}{ Age } \\
\hline$<65$ years & $139(46.3)$ & $31(10.4)$ & $126(42.0)$ & $36(12.0)$ & $1.28(0.75-2.19)$ \\
\hline$\geq 65$ years & $108(36.0)$ & $22(7.3)$ & $105(35.0)$ & $33(11.0)$ & $1.54(0.85-2.82)$ \\
\hline \multicolumn{6}{|l|}{ Gender } \\
\hline Male & $169(56.3)$ & $33(11.0)$ & $168(56.0)$ & $41(13.7)$ & $1.25(0.75-2.08)$ \\
\hline Female & $81(27.0)$ & $17(5.7)$ & $66(22.0)$ & $25(8.3)$ & $1.81(0.90-3.62)$ \\
\hline \multicolumn{6}{|l|}{ Smoking history } \\
\hline No & $146(48.7)$ & $37(12.3)$ & $115(38.3)$ & $40(13.3)$ & $1.37(0.83-2.28)$ \\
\hline Yes & $106(35.3)$ & $11(3.7)$ & $117(39.0)$ & $28(9.4)$ & $2.31(1.09-4.86)$ \\
\hline \multicolumn{6}{|l|}{ Drinking history } \\
\hline No & $105(35.0)$ & $12(4.0)$ & $72(24.0)$ & $15(5.0)$ & $1.82(0.80-4.12)$ \\
\hline Yes & $162(54.0)$ & $21(7.0)$ & $157(52.3)$ & $56(18.7)$ & $2.75(1.59-4.76)$ \\
\hline \multicolumn{6}{|l|}{ Family history } \\
\hline No & $236(78.7)$ & 35 (11.6) & $204(68.0)$ & $42(14.0)$ & $1.39(0.85-2.26)$ \\
\hline Yes & $21(7.0)$ & $8(2.7)$ & $24(8.0)$ & $30(10.0)$ & $3.28(1.24-8.70)$ \\
\hline
\end{tabular}

${ }^{\mathrm{a}} \mathrm{P}<0.05$ vs. no smoking history; ${ }^{\mathrm{b}} \mathrm{P}<0.05$ vs. no drinking history; ${ }^{\mathrm{C}}<0.05$ vs. no family history. $\mathrm{CRC}$, colorectal cancer; $\mathrm{OR}$, odds ratio; $\mathrm{CI}$, confidence interval.

Table VI. Associations between COX-2 rs20417 G/C single-nucleotide polymorphism and biological behaviors in colorectal cancer.

COX-2 rs $20417 \mathrm{G} / \mathrm{C}$

\begin{tabular}{|c|c|c|c|c|c|}
\hline Pathological features & $\mathrm{n}$ & GG (\%) & GC (\%) & $\mathrm{CC}(\%)$ & $\mathrm{GC}+\mathrm{CC}(\%)$ \\
\hline \multicolumn{6}{|l|}{ Location } \\
\hline Colon & 144 & $27(18.8)$ & 63 (43.7) & $54(37.5)$ & 117 (81.2) \\
\hline Rectum & 156 & $33(21.2)$ & $54(34.6)$ & $69(44.2)$ & $123(78.8)$ \\
\hline OR $(95 \% \mathrm{CI})$ & & $0.70(0.38-1.31)$ & $1.05(0.56-1.95)$ & $0.86(0.49-1.31)$ & \\
\hline \multicolumn{6}{|l|}{ Lymphatic metastasis } \\
\hline No & 168 & $47(28.0)$ & $58(34.5)$ & $63(37.5)$ & $121(72.0)$ \\
\hline Yes & 132 & $13(9.8)$ & $41(31.1)$ & $78(59.1)$ & $119(90.2)$ \\
\hline OR $(95 \% \mathrm{CI})$ & & $2.56(1.23-5.32)^{\mathrm{a}}$ & $4.48(2.23-9.00)^{\mathrm{a}}$ & $3.56(1.83-6.91)^{\mathrm{a}}$ & \\
\hline \multicolumn{6}{|l|}{ TNM stage } \\
\hline $\mathrm{I} / \mathrm{II}$ & 156 & $54(28.2)$ & $61(45.5)$ & $41(26.3)$ & $102(71.8)$ \\
\hline III/IV & 144 & $27(18.8)$ & $63(43.7)$ & $54(37.5)$ & $117(81.2)$ \\
\hline OR $(95 \% \mathrm{CI})$ & & $2.07(1.16-3.69)^{\mathrm{b}}$ & $2.63(1.42-4.87)^{\mathrm{b}}$ & $2.30(1.35-3.91)^{\mathrm{b}}$ & \\
\hline
\end{tabular}

${ }^{\mathrm{a}} \mathrm{P}<0.05$ vs. no lymphatic metastasis; ${ }^{\mathrm{b}} \mathrm{P}<0.05$ vs. TNM stage I/II. COX-2, cyclooxygenase-2; OR, odds ratio; CI, confidence interval; TNM, tumor-node-metastasis.

GG genotype carriers in healthy controls $(\mathrm{OR}=3.28 ; 95 \% \mathrm{CI}$, 1.24-8.70; $\mathrm{P}<0.05)$.

Association of COX-2 rs20417 G/C and rs2745557 G/A polymorphism with CRC disease status. The associations between
COX-2 genotypes and tumor stage or grade, as determined at the time of diagnosis, were further evaluated. Significant associations were not observed between COX-2 genotypes and disease location of CRC; however, the results revealed that TNM stage of $\mathrm{CRC}$ at diagnosis was associated with the COX-2 rs20417 G/C 
Table VII. Associations between COX-2 rs2745557 G/A single-nucleotide polymorphism and biological behaviors in colorectal cancer.

COX-2 rs20417G/C

\begin{tabular}{lccccc}
\cline { 3 - 5 } Pathological features & $\mathrm{n}$ & $\mathrm{GG}(\%)$ & $\mathrm{GC}(\%)$ & $\mathrm{CC}(\%)$ & $\mathrm{GC}+\mathrm{CC}(\%)$ \\
\hline Part & & & & & \\
$\quad$ Colon & 144 & $26(18.1)$ & $60(41.7)$ & $58(40.2)$ & $118(81.9)$ \\
Rectum & 156 & $23(14.7)$ & $63(40.4)$ & $70(44.9)$ & $133(85.3)$ \\
OR $(95 \%$ CI) & & & $1.19(0.61-2.30)$ & $1.36(0.71-2.64)$ & $1.27(0.69-2.35)$ \\
Lymphatic metastasis & & & & \\
No & 168 & $58(34.5)$ & $35(20.8)$ & $75(44.7)$ & $110(65.5)$ \\
Yes & 132 & $21(15.9)$ & $30(22.7)$ & $81(61.4)$ & $111(84.1)$ \\
OR $(95 \%$ CI) & & $2.36(1.18-4.76)^{\mathrm{a}}$ & $2.98(1.65-5.38)^{\mathrm{a}}$ & $2.79(1.59-4.90)^{\mathrm{a}}$ & \\
TNM stage & & & & \\
I/II & 156 & $55(35.3)$ & $40(25.6)$ & $61(39.1)$ & $101(64.7)$ \\
III/IV & 144 & $14(9.7)$ & $33(22.9)$ & $97(67.4)$ & $130(90.3)$ \\
OR $(95 \%$ CI) & & $3.24(1.54-6.84)^{\mathrm{b}}$ & $6.25(1.87-4.91)^{\mathrm{b}}$ & $5.06(2.66-9.61)^{\mathrm{b}}$ & \\
\hline
\end{tabular}

${ }^{\mathrm{a}} \mathrm{P}<0.05$ vs. no lymphatic metastasis; ${ }^{\mathrm{b}} \mathrm{P}<0.05$ vs. TNM stage I/II. COX-2, cyclooxygenase-2; OR, odds ratio; CI, confidence interval; TNM, tumor-node-metastasis.

and rs2745557 G/A polymorphisms. As shown in Tables VI and VII, the allelic frequencies of COX-2 rs20417 G/C (GG, $18.8 \%$; GC, $43.7 \%$; CC, 37.5\%) and rs $2745557 \mathrm{G} / \mathrm{A}$ (GG, 9.7\%; GA, 22.9\%; AA, 67.4\%) in stage III/IV CRC were significantly different from COX-2 rs $20417 \mathrm{G} / \mathrm{C}(\mathrm{GG}, 28.2 \%$; GC, 45.5\%; $\mathrm{CC}, 26.3 \%)$ and rs2745557 G/A (GG, 35.3\%; GA, 25.6\%; AA, $39.1 \%)$ in stage $\mathrm{I} / \mathrm{II}$ CRC $(\mathrm{P}<0.05)$. In addition, the COX-2 rs20417 G/C and rs2745557 G/A genotype was demonstrated to be significantly associated with lymph node metastasis. The allelic frequencies of the COX-2 rs $20417 \mathrm{G} / \mathrm{C}(\mathrm{GG}, 9.8 \%$; GC, $31.1 \%$; CC, $59.1 \%$ ) and rs $2745557 \mathrm{G} / \mathrm{A}$ (GG, $15.9 \%$; GA, 22.7\%; $\mathrm{AA}, 61.4 \%$ ) in patients with lymph node metastasis were significantly different from COX-2 rs20417 G/C (GG, 28.0\%; GC, 34.5\%; CC, 37.5\%) and rs 2745557 G/A (GG, 34.5\%; GA, 20.8\%; AA, $44.7 \%$ ) in patients without lymph node metastasis. These results indicated that patients with $\mathrm{CRC}$, who express a COX-2 rs20417 C allele (GC or CC genotype) and/or a COX-2 rs2745557 A allele (GA or AA genotype) had a markedly increased risk of developing higher stages of CRC, including high-grade CRC and lymph node metastasis.

\section{Discussion}

The present study aimed to investigate the correlation between polymorphisms in the COX-2 promoter region (rs20417 G/C and rs2745557 G/A) and the risk of CRC. Genotyping of 300 CRC patients and 300 healthy controls was performed in a Han Chinese population in Shaanxi, China. The results revealed that COX-2 rs20417 G/C and rs2745557 G/A polymorphisms were associated with a greater risk of developing CRC. In addition, these results demonstrated that the COX-2 rs $20417 \mathrm{G} / \mathrm{C}$ and rs $2745557 \mathrm{G} / \mathrm{A}$ polymorphisms were associated with metastatic CRC and that patients with these variant alleles had a greater susceptibility to the development of advanced CRC. Based on these results, it was suggested that the functional variants of COX-2 may result in susceptibility to cancer and therefore have an important role in colorectal carcinogenesis.

Case-control studies have been performed in several countries and different ethnic populations (20-23). In line with the results of the present study, a previous study in a Singapore Chinese population indicated that the COX-2 rs20417 C allele was associated with an elevated susceptibility for colon cancer (20). In addition, a previous study in a Spanish population revealed that a COX-2 polymorphism in the untranslated region of exon 10 was associated with a greater risk of CRC (24). By contrast, a certain study reported that the COX-2 rs 20417 Callele was associated with a reduced risk of colorectal adenoma in non-users of NSAIDs in a Caucasian American population (21). Furthermore, COX-2 polymorphism of an amino acid substitution was correlated with a decreased risk of colorectal neoplasia in an African-American population $(22,23)$. Therefore, there is difference between COX-2 polymorphisms and CRC risk among various ethnic populations; however, the biological function of the COX-2 polymorphism remains elusive $(24,25)$.

Although the invasion and metastasis of CRC are a prominent cause of cancer-associated mortality worldwide, the initial pathogenesis of CRC remains to be fully elucidated. Several studies have demonstrated that COX-2 overexpression was associated with the invasive capacity of colon cancer cells and advanced stages of CRC $(26,27)$. In addition, COX-2 and its downstream prostaglandins are strongly correlated with cell proliferation, angiogenesis and immunosuppression, all of which may be involved in the development of advanced stages of CRC (28-30). In the present study, the COX-2 rs20417 C allele and rs2745557 A allele were revealed to be associated with an enhanced susceptibility to high-grade CRC. Based on these findings, it was speculated that COX-2 may be involved in the tumorigenesis and progression of $\mathrm{CRC}$, as the COX-2 
rs20417 C allele and rs2745557 A allele were found to be significantly correlated with the risk of CRC progression.

In conclusion, the results of the present study demonstrated that the COX-2 rs20417 G/C and rs2745557 G/A polymorphisms were factors which were associated with genetic susceptibility for developing CRC in a Han Chinese population. In addition, the present study revealed that the COX-2 rs20417 G/C and rs2745557 G/A alleles were associated with an enhanced susceptibility for the advanced stages of CRC. Furthermore, these findings were in concurrence with the biological functions associated with these polymorphisms and confirmed the hypothesis that genetic polymorphisms in the COX-2 promotor region, which result in altered protein expression and/or activity, may mediate the inflammatory response, resulting in altered susceptibility to CRC.

\section{Acknowledgements}

The present study was funded by programs from the National Natural Science Foundation of China (General Program no. 30771895).

\section{References}

1. Lashner BA, Silverstein MD and Hanauer SB: Hazard rates for dysplasia and cancer in ulcerative colitis. Results from a surveillance program. Dig Dis Sci 34: 1536-1541, 1989.

2. Lennard-Jones JE, Morson BC, Ritchie JK, et al: Cancer in colitis: Assessment of the individual risk by clinical and histological criteria. Gastroenterology 73: 1280-1289, 1977.

3. Rhodes JM and Campbell BJ: Inflammation and colorectal cancer: IBD associated and sporadic cancer compared. Trends Mol Med 8: 10-16, 2002.

4. Romano $\mathrm{M}$ and Claria J: Cyclooxygenase-2 and 5-lipoxygenase converging functions on cell proliferation and tumor angiogenesis: Implications for cancer therapy. FASEB J 17: 1986-1995, 2003.

5. Simmons DL, Botting RM and Hla T: Cyclooxygenase isozymes: The biology of prostaglandin synthesis and inhibition. Pharmacol Rev 56: 387-437, 2004.

6. Tsujii M, Kawano S, Tsuji S, et al: Cyclooxygenase regulates angiogenesis induced by colon cancer cells. Cell 93: 705-716, 1998.

7. Ranger GS, Thomas V, Jewell A and Mokbel K: Elevated cyclooxygenase- 2 expression correlates with distant metastases in breast cancer. Anticancer Res 24: 2349-2351, 2004.

8. Eberhart CE, Coffey RJ, Radhika A, et al: Up-regulation of cyclooxygenase 2 gene expression in human colorectal adenomas and adenocarcinomas. Gastroenterology 107: 1183-1188, 1994.

9. Ristimäki A, Honkanen N, Jänkälä $\mathrm{H}$, et al: Expression of cyclooxygenase-2 in human gastric carcinoma. Cancer Res 57: 1276-1280, 1997.

10. Liu X,LiP,Zhang ST, et al: COX-2 mRNA expression in esophageal squamous cell carcinoma (ESCC) and effect by NSAID. Dis Esophagus 21: 9-14, 2008

11. Brosens LA, Donahue CA, Keller JJ, et al: Increased cyclooxygenase-2 expression in duodenal compared with colonic tissues in familial adenomatous polyposis and relationship to the $-765 \mathrm{G} / \mathrm{C}$ COX-2 polymorphism. Clin Cancer Res 11: 4090-4096, 2005.

12. Fritsche E, Baek SJ, King LM, Zeldin DC, Eling TE and Bell DA: Functional characterization of cyclooxygenase-2 polymorphisms. J Pharmacol Exp Ther 299: 468-476, 2001.

13. Papafili A, Hill MR, Brull DJ, et al: Common promoter variant in cyclooxygenase-2 represses gene expression: Evidence of role in acute-phase inflammatory response. Arterioscler Thromb Vasc Biol 22: 1631-1636, 2002.
14. Hamajima N, Takezaki T, Matsuo K, et al: Genotype frequencies of cyclooxygenease 2 (COX2) rare polymorphisms for Japanese with and without colorectal cancer. Asian Pac. Asian Pac J Cancer Prev 2: 57-62, 2001

15. Lee TS, Jeon YT, Kim JW, et al: Lack of association of the cyclooxygenase- 2 and inducible nitric oxide synthase gene polymorphism with risk of cervical cancer in Korean population. Ann N Y Acad Sci 1095: 134-142, 2007.

16. Zhang X, Miao X, Tan W, et al: Identification of functional genetic variants in cyclooxygenase-2 and their association with risk of esophageal cancer. Gastroenterology 129: 565-576, 2005.

17. Szczeklik W, Sanak M, Szczeklik A, et al: Functional effects and gender association of COX-2 gene polymorphism G-765C in bronchial asthma. J Allergy Clin Immunol 114: 248-253, 2004.

18. Hermanek P, Scheibe O, Spiessl B and Wagner G: TNM classification of malignant tumors: The new 1987 edition. Rontgenblatter 40: 200, 1987 (In German).

19. Hamilton SR, Bosman FT, Boffetta P, et al: Tumours of the colon and rectum. In: WHO Classification of Tumours of the Digestive System. Bosman FT, Carneiro F, Hruban RH and Theise ND (eds). IARC Press, Lyon: pp131-181, 2010.

20. Koh WP, Yuan JM, Van Den Berg D, et al: Interaction between cyclooxygenase- 2 gene polymorphism and dietary n- 6 polyunsaturated fatty acids on colon cancer risk: The Singapore Chinese Health Study. Br J Cancer 90: 1760-1764, 2004.

21. Ulrich CM, Whitton J, Yu JH, et al: PTGS2 (COX-2) -765G $>C$ promoter variant reduces risk of colorectal adenoma among nonusers of nonsteroidal anti-inflammatory drugs. Cancer Epidemiol Biomarkers Prev 14: 616-619, 2005.

22. Lin HJ, Keku TO, Reddy ST, et al: Prostaglandin H synthase 2 variant (Val511Ala) in African Americans may reduce the risk for colorectal neoplasia. Cancer Epidemiol Biomarkers Prev 11: 1305-1315, 2002.

23. Sansbury LB, Millikan RC, Schroeder JC, et al: COX-2 polymorphism, use of nonsteroidal anti-inflammatory drugs and risk of colon cancer in African Americans (United States). Cancer Causes Control 17: 257-266, 2006.

24. Goodman JE, Bowman ED, Chanock SJ, et al: Arachidonate lipoxygenase (ALOX) and cyclooxygenase (COX) polymorphisms and colon cancer risk. Carcinogenesis 25: 2467-2472, 2004.

25. Cox DG, Pontes C, Guino E, Navarro M, Osorio A, Canzian F, Moreno V; Bellvitge Colorectal Cancer Study Group: Polymorphisms in prostaglandin synthase 2/cyclooxygenase 2 (PTGS2/COX2) and risk of colorectal cancer. Br J Cancer 91: 339-343, 2004.

26. Tomozawa S, Tsuno NH, Sunami E, et al: Cyclooxygenase-2 overexpression correlates with tumour recurrence, especially haematogenous metastasis, of colorectal cancer. Br J Cancer 83: 324-328, 2000.

27. Zhang H and Sun XF: Overexpression of cyclooxygenase-2 correlates with advanced stages of colorectal cancer. Am J Gastroenterol 97: 1037-1041, 2002.

28. Konno H, Baba M, Shoji T, Ohta M, Suzuki S and Nakamura S: Cyclooxygenase-2 expression correlates with uPAR levels and is responsible for poor prognosis of colorectal cancer. Clin Exp Metastasis 19: 527-534, 2002.

29. Yao M, Lam EC, Kelly CR, Zhou W and Wolfe MM: Cyclooxygenase-2 selective inhibition with NS-398 suppresses proliferation and invasiveness and delays liver metastasis in colorectal cancer. Br J Cancer 90: 712-719, 2004.

30. Tsujii M, Kawano S and DuBois RN: Cyclooxygenase-2 expression in human colon cancer cells increase metastatic potential. Proc Natl Acad Sci USA 94: 3336-3340, 1997. 